\title{
PERKEMBANGAN BALITA USIA 6-60 BULAN \\ BERDASARKAN KEJADIAN ANEMIA DAN PEMBERIAN STIMULASI MELALUI PENDIDIKAN ANAK USIA DINI
}

\author{
Endah Puji Astuti ${ }^{1}$ \\ ${ }^{1}$ Program Studi Kebidanan Stikes Jenderal Achmad Yani Yogyakarta, Jl. Ringroad Barat Ambarketawang \\ Gamping Sleman, Telp. (0274) 4342000, Email: endahpujiastuti14@yahoo.co.id
}

\begin{abstract}
Background: Children development is measured by four aspects; motoric skills, language, behavior, and mental development. Early childhood development was influenced by maternal nutrition during pregnancy, infant nutrition, stimulation, and parents' knowledge.

Objective: This study aimed to describe the development of children aged 6-60 months subject to anemia and stimulation through early childhood education.

Method: The study was quantitative descriptive with 158 toddlers involved as respondents. Tools and materials used in this study were digital haemometer and DDST sheets.

Result: Toddlers with normal development and suspect were majority experienced mild anemia $(34.81 \%$, $14,56 \%$, respectively). While toddlers who followed early childhood education, majority had normal development $(45.57 \%)$. Non-participating early childhood education tended to have developmental suspect (23.4\%). Three toddlers with severe anemia ( $\mathrm{Hb} 7.2$ to $7.9 \mathrm{~g} \%$ ) had normal development, presumably due to early childhood education and one toddler with severe anemia ( $\mathrm{Hb} 6 \mathrm{gr} \%)$ and not attending early education had suspected development.

Conclusion: Toddlers with or without anemia had equal development, while toddlers who were given stimulation through early childhood education tended to have normal development.
\end{abstract}

Key Word: early childhood development, anemia, stimulation of early childhood education

\section{PENDAHULUAN}

Pembangunan nasional bertujuan meningkatkan kualitas sumber daya manusia (SDM) secara berkesinambungan dan berkelanjutan. Kualitas sumber daya manusia ditentukan oleh keberhasilan tumbuh kembang pada masa kanak-kanak. Investasi yang dimulai sejak dini (usia anak-anak) dianggap paling menguntungkan di dalam pembangunan SDM. ${ }^{(1)}$

Perkembangan (development) adalah bertambahnya kemampuan dalam struktur dan fungsi tubuh yang lebih kompleks dalam pola yang teratur dan dapat diramalkan. Sebagai hasil dari proses pematangan, di sini menyangkut adanya proses diferensiasi dari sel-sel tubuh, jaringan tubuh, organ-organ, dan system organ yang berkembang sedemikaian rupa sehingga masing-masing dapat memenuhi fungsinya termasuk juga perkembangan emosi, intelektual, dan tingkah laku sebagai hasil interaksi dengan lingkungan. ${ }^{(2)}$

Menurut Soetjiningsih dalam Rusana (2008), usia dini merupakan fase awal perkembangan anak yang akan menentukan pekembanang selanjutnya. Perkembangan awal terbagi menjadi empat aspek kemampuan fungsional yaitu motorik kasar, motorik halus, bahasa serta sosial emosi, dan perilaku. Jika terjadi kekurangan pada salah satu aspek, maka akan memengaruhi 
perkembangan aspek lainnya.

Perkembangan balita dipengaruhi oleh sataus gizi ibu saat hamil, status gizi balita, stimulasi, pengetahuan ibu. ${ }^{(3)}$

Dalam Supariasa, dkk ( 2002). Faktor utama yang memengaruhi tumbuh kembang anak di antaranya adalah faktor gizi, kesehatan, dan pengasuhan (caring) yang terkait satu sama lain. Anak kekurangan gizi memiliki IQ yang kurang, hal ini bukan hanya disebabkan oleh makanan saja, tetapi lebih disebabkan oleh kekurangan stimulus dari orang tua yang biasanya juga menderita kekurangan gizi. ${ }^{(4)}$

Hasil wawancara dari ibu balita di Desa Ambarketawang, didapatkan $60 \%$ di antaranya mengatakan anaknya susah makan sayur dan lebih suka makan jajanan atau minum susu formula yang dalam satu hari dapat menghabiskan lebih dari enam botol, sehingga ibu lebih memilih memberikan makanan yang disukai anaknya atau susu formula daripada tidak makan. Informasi dari kader balita pada lima posyandu, sekitar 30\% di antaranya balita memiliki perkembangan yang tidak sesuai dengan usianya. Kejadiannya lebih besar jika dibandingkan dengan desa lain di Kecamatan Gamping. Balita di Desa Ambarketawang belum pernah dilakukan pemeriksaan hemoglobin. Penelitian ini bertujuan untuk mengetahui perkembangan balita berdasarkan kejadian anemia dan perkembangan balita berdasarkan pemberian stimulasi melalui pendidikan anak usia dini di desa
Ambarketawang Gamping Sleman Yogyakarta.

\section{BAHAN DAN CARA PENELITIAN}

Jenis penelitian ini adalah merupakan penelitian deskriptif. Populasi dalam penelitian adalah semua balita usia 6-60 bulan di Desa Ambarketawang Gamping Sleman Yogyakarta yang mengikuti posyadu yaitu sebanyak 603. Sampel diambil dengan tehnik probality sampling yaitu cluster random sampling, dari 13 padukuhan diambil 8 padukuhan sebanyak 158 balita. Analisis data yang digunakan yaitu analisis univariat dengan persentase.

\section{HASIL DAN PEMBAHASAN}

Perkembangan balita di Desa Ambarketawang mayoritas nomal dan sebagian besar mengalami anemia ringan. Balita dikatakan tidak anemia ( $\mathrm{Hb} \geq 11 \mathrm{gr} \%$ ), anemia ringan ( $\mathrm{Hb}$ 9,5-10,9gr\%), anemia sedang $(\mathrm{Hb} 8-9,4 \mathrm{gr} \%)$ dan anemia berat $(\mathrm{Hb}$ $<8)$. Tiga balita perkembangan normal dengan anemia berat, kadar hemoglobin 7,27,9 gr\% dan satu balita dengan perkembangan suspect memiliki kadar hemoglobin 6 gr\%, yang tercantum pada tabel berikut.

Tabel 1. Perkembangan Balita Berdasarkan Kejadian Anemia. Kejadian anemia

\begin{tabular}{|c|c|c|c|c|c|c|c|c|c|c|}
\hline \multirow{3}{*}{$\begin{array}{l}\text { Perkem- } \\
\text { bangan }\end{array}$} & \multirow{2}{*}{\multicolumn{2}{|c|}{$\begin{array}{c}\text { Tidak } \\
\text { Anemia }\end{array}$}} & \multirow{2}{*}{\multicolumn{2}{|c|}{$\begin{array}{l}\text { Anemia } \\
\text { Ringan }\end{array}$}} & \multirow{2}{*}{\multicolumn{2}{|c|}{$\begin{array}{l}\text { Anemia } \\
\text { sedang }\end{array}$}} & \multirow{2}{*}{\multicolumn{2}{|c|}{$\begin{array}{c}\text { Anemia } \\
\text { berat }\end{array}$}} & & \\
\hline & & & & & & & & & \multicolumn{2}{|c|}{ Total } \\
\hline & $f$ & $\%$ & $f$ & $\%$ & $f$ & $\%$ & $f$ & $\%$ & $f$ & $\%$ \\
\hline Normal & 41 & 37 & 55 & 50 & 11 & 10 & 3 & 3 & 110 & 100 \\
\hline Suspect & 21 & 44 & 23 & 48 & 3 & 6 & 1 & 2 & 48 & 100 \\
\hline
\end{tabular}

(Sumber: data primer 2015) 
Balita di Desa Ambarketawang sebagian besar mengikuti pendidikan anak usia dini (PAUD) dan mayoritas memiliki perkembangan normal, yang tercantum pada tabel berikut.

Tabel 2. Perkembangan Balita Dilihat Dari Pemberian Stimulasi Melalui Pendidikan Anak Usia Dini

\begin{tabular}{lcccccc}
\hline \multirow{2}{*}{ Perkembangan } & \multicolumn{6}{c}{ PAUD } \\
\cline { 2 - 8 } & \multicolumn{2}{c}{$\begin{array}{l}\text { Ikut } \\
\text { PAUD }\end{array}$} & \multicolumn{2}{c}{ Tidak PAUD } & \multicolumn{2}{c}{ Total } \\
\cline { 2 - 7 } & $\mathrm{f}$ & $\%$ & $\mathrm{f}$ & $\%$ & $\mathrm{f}$ & $\%$ \\
\hline Normal & 72 & 65 & 38 & 35 & 110 & 100 \\
\hline Sucpect & 11 & 23 & 37 & 77 & 48 & 100 \\
\hline
\end{tabular}

(Sumber: data primer 2015)

Perkembangan normal jika balita dapat melakukan semua perkembangan (lulus atau passed) berdasarkan garis usia pada area $75-90 \%$ atau hanya mengalami satu kewaspadaan, (gagal atau fail) pada salah satu sektor perkembangan yang dinilai, sedangkan suspect jika satu atau dua lebih kelambatan dan/atau dua atau lebih banyak kewaspadaan. ${ }^{(3)}$

Hasil penelitian didapatkan 110 balita $(69,62 \%)$ perkembangan normal dan 48 balita $(30,38 \%) \quad$ suspect. Perkembangan balita dilihat dari kadar haemoglobin, balita yang memiliki perkembangan normal maupun suspect mayoritas mengalami anemia ringan yaitu 55 balita (50\%) perkembangan normal dan 23 balita (48\%) perkembangan suspect. Dilihat dari jumlahnya, balita yang tidak anemia mayoritas memiliki perkembangan normal. Balita yang tidak anemia maupun anemia berat memiliki kemungkinan yang sama mengalami perkembangan normal, sehingga dalam tabel 1 dapat disimpulkan bahwa anemia tidak mempengaruhi perkembangan balita.

Penelitian ini tidak sesuai dengan teori Purnamasari (2008) bahwa pengaruh anemia balita terhadap fungsi kognitif terjadi penurunan sehingga kecerdasan anak berkurang, kurang atensi (perhatian), dan prestasi belajar terganggu. Serta tidak sesuai dengan hasil penelitian Zulaekah (2014) bahwa secara statistik tidak terdapat beda nyata terhadap laju pertumbuhan dan tingkat perkembangan antara anak malnutrisi yang anemia dengan yang tidak anemia, namun hasil penelitian tersebut memberikan indikasi bahwa perkembangan anak (motorik kasar, motorik halus, dan perkembangan bahasa) pada anak malnutrisi yang anemia lebih rendah dibandingkan dengan anak malnutrisi yang tidak anemia.

Balita yang memiliki perkembangan normal mayoritas mengikuti PAUD dan yang tidak mengikuti PAUD cenderung memiliki perkembangan suspect. Dari balita yang memiliki perkembanagn normal, sebanyak 72 (65\%) mengikuti PAUD dan 38 (35\%) tidak mengikuti PAUD, sedangkan balita yang memiliki perkembangan suspect 11 (23\%) mengikuti PAUD dan 37 (77\%) tidak mengikuti PAUD. Tiga balita anemia berat ( $\mathrm{Hb}$ 7,2-7,9 gr\%) memiliki perkembangan normal karena mengikuti PAUD dan satu balita anemia berat ( $\mathrm{Hb} 6 \mathrm{gr} \%$ ) yang tidak mengikuti PAUD memiliki perkembangan suspect. 
Menurut Wahyuni (2004), anemia akan memengaruhi kekebalan tubuh anak, anak menjadi lemah, letih, kehilangan nafsu makan, menurunnya daya kosentrasi, dan sakit kepala, sehingga menurunkan fungsi kognitif serta motorik anak. Meskipun demikian jika balita diberikan stimulasi terus menerus sesuai usia perkembangan, akan memiliki perkembangan yang normal dan sebaliknya jika gizi baik namun tidak diberikan stimulasi akan menyebabkan perkembangan sucpect. Pendidikan anak usia dini (PAUD) merupakan suatu upaya pembinaan bagi anak sejak lahir sampai dengan enam tahun yang dilakukan melalui pemberian rangsangan pendidikan untuk membantu petumbuhan dan perkembangan jasmani dan rohani yang optimal.

Melalui pendidikan anak usia dini anak maka anak akan mendapatkan stimulasi perkembangannya yang meliputi empat aspek yaitu 1) personal social yang berhubungan dengan kemandirian, bersosialisasi dan berinteraksi dengan lingkungannya, 2) fine motor adaptive yang berhubungan dengan kemampuan anak untuk mengamati sesuatu, melakukan gerakan yang melibatkan bagian-bagian tubuh tertentu dan dilakukan oleh otot-otot kecil yang memerlukan koordinasi yang cermat, 3) language yaitu kemampuan untuk memberikan respons terhadap suara, mengikuti perintah dan berbicara spontan, 4) gross motor yang berhubungan dengan gerakan dan sikap tubuh. ${ }^{(3)}$

\section{KESIMPULAN}

Balita memiliki perkembangan sama antara yang mengalami anemia dan tidak anemia, balita dengan perkembangan normal dan suspect mayoritas mengalami anemia ringan. Sedangkan balita yang diberikan stimulasi melalui pendidikan anak usia dini cenderung memiliki perkembangan normal dan sebaliknya balita yang tidak mendapatkan stimulasi perkembangan dari pendidikan anak usia dini mengalami perkembangan suspect. Meskipun mengalami anemia berat, 3 balita tetap memiliki perkembangan normal. Saran bagi orangtua tidak hanya memperhatikan asupan gizi, namun harus memberikan stimulasi dini pada balita untuk mencapai perkembangan yang optimal. Penting bagi orangtua untuk memahami perkembangan sosial, kognitif, emosional, dan pendidikan anak. Orang tua yang sibuk bekerja dapat menitipkan anaknya di PAUD.

\section{KEPUSTAKAAN}

1. Departemen Kesehatan RI. Manajemen laktasi buku panduan bagi bidan dan petugas kesehatan di puskesmas. 2005 http://www.depkes.go.id. Diakses 10 April 2015.

2. Nursalam, dkk. Asuhan keperawatan bayi dan anak (untuk perawat dan bidan) edisi 1. Jakarta : Salemba Medika. (2005)

3. Rusana. Perkembangan Menurut Denver II $\quad$ (DDST 2008. 
http://www.rofiqahmad.wordpress.com.

Diakses 25 September 2015.

4. Supariasa, I Dewa Nyoman. Penilaian status gizi. Jakarta : EGC. 2002.

5. Purnamasari, DU. Analisis pemberian asi eksklusif dan susu formula terhadap goncangan pertumbuhan. 2008. Jurnal Kesmas Vol 1.

6. Zulaekah S, Setyo P dan Listyani H. Anemia terhadap pertumbuhan dan perkembangan anak malnutrisi. 2014. Jurnal Kesehatan Masyarakat Volume 2, Nomer 9 hal 106-114. http://journal.unnes.ac.id/nju/index.php/ke mas.

7. Wahyuni, AS. Anemia defisiensi besi pada balita. 2004. Digitized by USU digital library. 